\title{
P044. Anger expression in chronic daily headache patients with and without psychiatric comorbidity
}

\author{
Giulia Giannini', Marialuisa Rausa, Sabina Cevoli, Valentina Favoni, Rossana Terlizzi, Pietro Cortelli, Giulia Pierangeli
}

From Abstracts from the 1st Joint ANIRCEF-SISC Congress

Rome, Italy. 29-31 October 2015

\section{Background}

Previous studies suggest the high prevalence of psychiatric comorbidity in chronic daily headache $(\mathrm{CDH})$ patients. In particular, $\mathrm{CDH}$ patients showed higher frequency of anxiety and depressive disorders than episodic migraineurs [1,2]. However, negative affect emotions (like depression, anxiety and anger) influence the course and impact of headache within the normal range of affective experience, not simply when an Axis I disorder is present [3].

In the literature it is reported that individuals with headache are more likely to hold their anger-in than controls. Individuals who hold anger-in experience an increased pain severity, failure to express anger leads to more disability $[4,5]$.

Anger levels in headache are supposed to be related to anxiety and depression [6,7], but one study showed that headache patients hold their anger-in more than controls, even after controlling for depression and anxiety [8].

The aim of this study was to investigate if anger expression levels in $\mathrm{CDH}$ patients are related to psychiatric comorbidity.

\section{Materials and methods}

Eighty-five CDH patients (19 M, 72 F) with and without medication overuse were recruited and assessed by Mini International Neuropsychiatric Interview (M.I.N.I.), and State-Trait Anger Expression Inventory (STAXI). On the basis of M.I.N.I. results patients were divided into two groups: with psychiatric comorbidity (group A) and without (group B). STAXI scores were compared between the two groups. T-test was performed to compare continuous variable between groups.

\footnotetext{
* Correspondence: giannini.giulia3@gmail.com Department of Biomedical and NeuroMotor Sciences (DIBINEM) Alma Mater Studiorum, University of Bologna, IRCCS Institute of Neurological Sciences of Bologna, Bologna, Italy
}

\section{Results}

According to the ICHD-II revised criteria, $4 \%$ of subjects had a diagnosis of CM, $19 \%$ of CTTH, and $77 \%$ of $\mathrm{MOH}$. Psychiatric comorbidity was detected in 39 patients (45.8\%) (group A) and was absent in the remaining 46 patients (54.1\%) (group B). The disorders most frequently diagnosed were mood and anxiety disorders (43.6\%). All STAXI scores were within the normative range, however the highest score was detected in the anger-in subscale, indicating a disposition to suppress rather than express angry feelings. No differences were found between patients with and without psychiatric comorbidity $(\mathrm{p}=0.316)$.

\section{Conclusions}

STAXI results showed no differences in the experience of anger between patients with and without psychiatric comorbidity. Interestingly the highest mean score was in the anger-in subscale that indicates the tendency to suppress anger expression instead of directing it towards people or objects. Patients with $\mathrm{CDH}$ appeared to a tendency to control their anger expression and transformation from episodic to chronic headache.

Written informed consent to publication was obtained from the patient(s).

\section{Published: 28 September 2015}

References

Rausa M, Cevoli S, Sancisi E, Grimaldi D, Pollutri G, Casoria M, Grieco D, Bisi A, Cortelli P, Pozzi E, Pierangeli G: Personality traits in chronic daily headache patients with and without psychiatric comorbidity: an observational study in a tertiary care headache center. $J$ Headache Pain 2013, 14(1):22.

2. Baskin SM, Lipchik GL, Smitherman T A: Mood and anxiety disorders in chronic headache. Headache 2006, 14(suppl 3):S76-S87. 
3. Nicholson RA, Houle TT, Rhudy JL, Norton PJ: Psychological risk factors in headache. Headache 2007, 47(3):413-26.

4. Perozzo P, Savi L, Castelli L, Valfrè W, Lo Giudice R, Gentile S, Rainero I, Pinessi L: Anger and emotional distress in patients with migraine and tension-type headache. J Headache Pain 2005, 6:392-399.

5. Kearns RD, Rosenberg R, Jacob MC: Anger expression and chronic pain. J Behav Med 1994, 17:57-67.

6. Abbate-Daga G, Fassino A, Lo Giudice R, Rainero I, Gramaglia C, Marech L, Amianto F, Gentile S, Pinessi L: Anger, depression and personality dimensions in patients with migraine without aura. Psychother Psychosom 2007, 76:122-128.

7. Venable $\mathrm{VL}$, Carlson $C R$, Wilson J: The role of anger and depression in recurrent headache. Headache 2001, 41:21-30.

8. Nicholson RA, Gramling SE, Ong JC, Buenevar L: Differences in anger expression between individuals with and without headache after controlling for depression and anxiety. Headache 2003, 43:651-663.

doi:10.1186/1129-2377-16-S1-A109

Cite this article as: Giannini et al:: P044. Anger expression in chronic daily headache patients with and without psychiatric comorbidity. The Journal of Headache and Pain 2015 16(Suppl 1):A109.

\section{Submit your manuscript to a SpringerOpen ${ }^{\mathcal{O}}$ journal and benefit from:}

- Convenient online submission

- Rigorous peer review

- Immediate publication on acceptance

- Open access: articles freely available online

- High visibility within the field

- Retaining the copyright to your article

Submit your next manuscript at $\gg$ springeropen.com 